\title{
COMPARAÇÃo DA EFICIÊNCIA DO PROCESSO DE OZONIZAÇÃO E OZONIZAÇÃo CATALÍTICA (Mn II E Cu II) NA DEGRADAÇÃO DE FENOL
}

\author{
Márcia Regina Assalin*e Priscila Lima da Silva \\ Departamento de Físico-Química, Instituto de Química, Universidade Estadual de Campinas, \\ CP 6154, 13084-971 Campinas-SP \\ Nelson Durán \\ Núcleo de Ciências Ambientais, Universidade de Mogi das Cruzes, Mogi das Cruzes -SP \\ Recebido em 3/9/04; aceito em 25/4/05; publicado na web em 10/8/05
}

\begin{abstract}
COMPARISON OF THE EFFICIENCY OF OZONATION AND CATALYTIC OZONATION (Mn II AND Cu II) IN PHENOL DEGRADATION. This paper discusses the results obtained with homogeneous catalytic ozonation [Mn (II) and Cu (II)] in phenol degradation. The reduction of total phenols and total organic carbon (TOC) and the ozone consumption were evaluated. The efficiency in phenol degradation (total phenol removal) at $\mathrm{pH} 3$, with the catalytic process (Mn (II)), increased from 37\% to 55\% while the TOC removal increased from 4 to $63 \%$ in a seven-minute treatment. The ozonation process efficiency at pH 10 was $43 \%$ and $39 \%$ for phenol and TOC removal, respectively. The presence of both metallic ions $\left(\mathrm{Mn}^{2+}\right.$ and $\left.\mathrm{Cu}^{+2}\right)$ in the ozonation process resulted in a positive effect.
\end{abstract}

Keywords: catalytic ozonation; metallic ions; phenol.

\section{INTRODUÇÃO}

O ozônio reage rapidamente com a maioria dos compostos orgânicos tipicamente presentes em efluentes industrias. Os subprodutos formados nessas reações de oxidação são geralmente compostos oxigenados de massa molecular reduzida (como ácidos orgânicos, cetonas e aldeídos), mais polares, hidrofílicos e biodegradáveis que seus precursores. $\mathrm{O}$ fato de tais compostos serem refratários à oxidação por ozônio, impede que a mineralização completa do efluente seja atingida constituindo, assim, uma das principais limitações deste processo ${ }^{1-4}$.

Inúmeros processos oxidativos avançados (POAs), tais como $\mathrm{O}_{3}$ I $\mathrm{H}_{2} \mathrm{O}_{2}, \mathrm{O}_{3} / \mathrm{UV}, \mathrm{O}_{3} /$ metais (ozonização catalítica), têm sido desenvolvidos numa tentativa de aumentar a eficiência do processo de ozonização. Esses processos são caracterizados pela formação do radical hidroxila $\left({ }^{\circ} \mathrm{OH}\right)$, que reage com a maioria das moléculas orgânicas com constantes reacionais da ordem de $10^{6}-10^{9} \mathrm{~mol}^{-1} \mathrm{~s}^{-11,2}$.

Dentro deste contexto, a ozonização catalítica (homogênea ou heterogênea) tem sido apontada, na literatura especializada, como sendo uma tecnologia de oxidação bastante promissora, aplicada à remoção de compostos orgânicos usualmente refratários aos tradicionais processos de oxidação $0^{5}$.

Numerosos metais (Fe, Mn, Ni, Co, Zn e Cr) sob várias formas (sais ou metais reduzidos, óxidos ou metais suportados) são citados na literatura como possíveis catalisadores do processo de ozonização ${ }^{6}$. De maneira geral, a ozonização catalítica possibilita a otimização do processo convencional, tendo em vista que a aplicação deste processo em meio ácido é bastante limitada devido à elevada estabilidade do ozônio.

A adição de metais no processo de ozonização resulta em aumento na razão de degradação da carga orgânica, redução do consumo de ozônio, além de evitar que determinados ânions (como carbonatos e bicarbonatos) interfiram na eficiência de oxidação

*e-mail: massalin@iqm.unicamp.br dos radicais hidroxilas eventualmente formados no processo ${ }^{5,7-9}$. Diversos trabalhos relatam a utilização de inúmeros sais metálicos na ozonização de efluentes ${ }^{9-14}$. Hewes e Davinson ${ }^{9}$ mostraram que a ozonização de efluentes na presença de Fe (II), Mn (II), Ni (II) e Co (II) resultou num aumento da eficiência de remoção de carbono orgânico total, em comparação ao processo de ozonização convencional (sem adição de catalisadores) ${ }^{9}$.

Andreozzi et al. ${ }^{10}$ ozonizaram soluções aquosas de ácido oxálico $\left(1,4 \times 10^{-3} \mathrm{~mol} \mathrm{~L}^{-1}\right)$ na presença de íons $\mathrm{Mn}^{+2}$ em diferentes concentrações e observaram que o íon metálico é realmente capaz de catalisar o processo de ozonização, embora diversos fatores possam influenciar a atividade catalítica do processo, como por ex., o $\mathrm{pH}$ do meio reacional. De acordo com os autores, o íon $\mathrm{Mn}^{+2}$ leva à formação de um complexo entre o ácido oxálico e a espécie $\mathrm{Mn}^{+3}$, dando origem a um composto intermediário que pode ser facilmente oxidado pelo ozônio (Figura 1$)^{10}$.

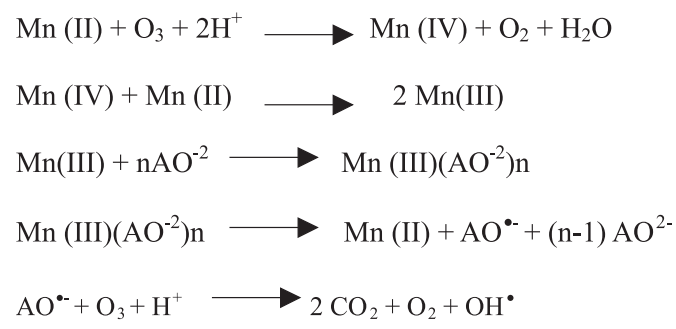

Figura 1. Esquema simplificado para o mecanismo para reação de oxidação química pelo ozônio na presença do catalisador $\left(\mathrm{Mn}^{+2}\right)$. Adaptada da ref. 10

Gracia et $a l .{ }^{15}$ estudaram a influência de íons metálicos $(6 \mathrm{x}$ $10^{-5} \mathrm{~mol} \mathrm{~L}^{-1}$ ) na eficiência do processo de ozonização no tratamento de soluções contendo ácidos húmicos. Dentre os íons me- 
tálicos estudados, o íon $\mathrm{Mn}^{+2}$ apresentou os melhores resultados, seguido pelo íon $\mathrm{Ag}^{+}$.

Ma e Graham ${ }^{11}$ estudaram a degradação da atrazina por ozônio utilizando três diferentes concentrações do íon Mn II $(0,5,1,0$ e $\left.1,5 \mathrm{mg} \mathrm{L}^{-1}\right)$. A razão de degradação da atrazina na presença do catalisador foi maior que aquela obtida pelo processo de ozonização somente. A razão de degradação do contaminante foi pouco afetada pela concentração do catalisador, o que significa que uma pequena dose do íon pode ser suficiente para uma razão de oxidação eficiente $^{11}$.

Ni et al. ${ }^{12}$ avaliaram o efeito catalítico de diversos íons metáli$\cos \left(\mathrm{Mn}^{+2}, \mathrm{Fe}^{+2}, \mathrm{Ti}^{+2}, \mathrm{Cu}^{+2}, \mathrm{~Pb}^{+2}, \mathrm{Zn}^{+2}\right)$ na ozonização do 2diclorofenol $\left(0,778 \mathrm{mmol} \mathrm{L}^{-1}\right)$. Dentre todos os íons utilizados, o $\mathrm{Mn}^{+2}$ foi o mais eficiente na degradação do 2-diclorofenol nas condições estudadas, seguido pelo $\mathrm{Ti}^{+2}$ e $\mathrm{Fe}^{+2}$. A remoção de carbono orgânico total aumentou de 11 para $38 \%$ na presença de $1 \mathrm{mg} \mathrm{L}^{-1}$ de $\mathrm{MnSO}_{4}$, em 20 min de ozonização ${ }^{12}$.

Arslan et al. ${ }^{16}$ compararam a eficiência dos processos $\mathrm{O}_{3} / \mathrm{Mn}^{+2} /$ $\mathrm{pH} 3$ e $\mathrm{O}_{3} / \mathrm{H}_{2} \mathrm{O}_{2} / \mathrm{pH}$ 7,5 na descoloração e remoção de DQO de um efluente têxtil sintético, preparado pela mistura de seis corantes reativos, sendo o $\mathrm{pH}$ deste efluente sintético igual a 10,9. Experimentos preliminares de otimização do processo foram realizados para indicar o $\mathrm{pH}$ e as doses de $\mathrm{H}_{2} \mathrm{O}_{2}$ e $\mathrm{Mn}^{+2}$ ideais. A cinética de descoloração para o processo $\mathrm{O}_{3} / \mathrm{Mn}^{+2} / \mathrm{pH}^{3}$ (ozonização catalítica) foi maior, embora a completa descoloração tenha sido atingida após 30 min de tratamento, para ambos os processos. A remoção de COD (carbono orgânico dissolvido) não foi significativa, sendo as porcentagens de remoção encontradas iguais a 11 e $6 \%$ para os processos $\mathrm{O}_{3} / \mathrm{H}_{2} \mathrm{O}_{2} / \mathrm{pH} 7,5$ e ozonização catalítica, respectivamente. $\mathrm{O}$ efeito da adiçãa do metal como catalisador do processo pode ter sido ocultado pela complexidade da matriz estudada, resultando em vários efeitos competitivos pelos radicais hidroxilas formados ${ }^{16}$.

Dentro do contexto de poluição ambiental, os fenóis são bastante relevantes. Representam a maior classe de poluentes orgânicos oriundos de diversas atividades industriais, tais como química, têxtil, plástica, farmacêutica, metalúrgica, refinarias de óleo, produção de pesticidas, resinas, papéis e explosivos ${ }^{17,18}$, sendo recalcitrantes à biodegradação e tóxicos à maioria dos microrganismos. Neste trabalho comparou-se a eficiência do processo de ozonização (via ozônio molecular e radical hidroxila) com a ozonização catalisada pelos íons $\mathrm{Mn}^{+2}$ e $\mathrm{Cu}^{+2}$ na degradação de fenol. Ácidos e aldeídos de baixo peso molecular têm sido identificados como os principais subprodutos da oxidação química de compostos fenólicos. Um exemplo típico é a formação de ácido oxálico, tipicamente refratário aos processos convencionais de oxidação química.

A eficiência dos processos foi avaliada pela razão de degradação do contaminante (medido como fenóis totais) e remoção de carga orgânica (carbono orgânico total - COT) em função do consumo de ozônio.

\section{PARTE EXPERIMENTAL}

\section{Solução padrão}

Foram utilizadas soluções aquosas de fenol em uma concentração de $0,8 \mathrm{mmol} \mathrm{L}^{-1}$.

\section{Controle analítico}

As medidas de $\mathrm{pH}$ foram determinadas utilizando-se o aparelho Orion modelo EA 940 da Cole Parmer, com eletrodo de vidro combinado, da mesma marca. Carbono Orgânico Total foi determinado utilizando um equipamento Shimadzu -TOC 5000, de acordo com a metodologia APHA ${ }^{19}$. A determinação de fenóis totais foi estimada colorimetricamente segundo o método Folin - Ciocalteu (APHA) ${ }^{19}$.

\section{Produção e medida de ozônio}

O ozônio foi gerado a partir de oxigênio puro, utilizando-se um ozonizador marca OZOCAV ZT-2 (Inter Ozone Ingenieria Ecológica, Santiago-Chile), instalado no próprio laboratório. Este equipamento tem capacidade para gerar ozônio a taxas entre 0,20 a $0,70 \mathrm{~g} \mathrm{~h}^{-1}$. O sistema utilizado para medida de ozônio (produzido e consumido) foi previamente descrito por Kunz e colaboradores ${ }^{20}$. Neste sistema um espectrofotômetro $(258 \mathrm{~nm})$ é interfaceado a um microcomputador, cujo programa de gerenciamento de interface permite fazer, além da aquisição e monitoramento dos dados, o tratamento das curvas (absorbância $\mathrm{x}$ tempo) que indicam a variação da concentração de ozônio proveniente do reator por unidade de tempo. O programa é capaz de calcular a concentração inicial de $\mathrm{O}_{3}$ através da Lei de Beer $\left(\varepsilon=2800 \mathrm{~L} \mathrm{~mol}^{-1} \mathrm{~cm}^{-1}\right)$ fazendo-se passar a mistura oxigênio-ozônio pela célula de fluxo. A intervalos de tempo previamente selecionados pelo usuário, os dados da curva são integrados e a quantidade de ozônio consumido é determinada para os intervalos selecionados ${ }^{20}$.

\section{Ozonização}

As soluções de fenol $(0,8 \mathrm{mmol} / \mathrm{L})$ foram submetidas aos processos de ozonização convencional e catalítico. A ozonização convencional foi realizada em dois diferentes pHs (3 e 10), ajustados pela adição de soluções aquosas de $\mathrm{H}_{2} \mathrm{SO}_{4}\left(2 \mathrm{~mol} \mathrm{~L}^{-1}\right)$ e $\mathrm{NaOH}(2$ mol L $\mathrm{L}^{-1}$ ), respectivamente. Os processos catalisados foram realizados somente em pH 3 na presença de $1 \mathrm{mg} \mathrm{L}^{-1}$ do íon metálico, obtidos a partir de soluções aquosas dos respectivos sais $\left(\mathrm{CuCl}_{2} \mathrm{e}\right.$ $\mathrm{MnCl}_{2}$ ). $\mathrm{O}$ processo catalítico foi realizado apenas em meio ácido com objetivo de priorizar a reação com fenol e comparar com a eficiência do processo de ozonização convencional em meio alcalino.

\section{RESULTADOS E DISCUSSÃO}

Fenóis são ácidos orgânicos fracos, facilmente desprotonados em meio alcalino, o que leva à formação do ânion fenolato. Com a desprotonação do fenol $\left(\mathrm{pK}_{\mathrm{a}}=10\right)$ a velocidade da reação de ozonização aumenta consideravelmente, o que pode ser demonstrado pela diferença existente entre as constantes reacionais ozônio-fenol $\left(1,3 \times 10^{3} \mathrm{dm}^{3} \mathrm{~mol}^{-1} \mathrm{~L}^{-1}\right)$ e ozônio-ânion fenolato $(1,4$ $\left.\mathrm{x} 10^{9} \mathrm{dm}^{3} \mathrm{~mol}^{-1} \mathrm{~L}^{-1}\right)^{22}$. As diferenças entre as velocidades reacionais ocorrem devido a dois fatores: aumento da concentração dos íons hidroxila em meio alcalino (capazes de iniciar a decomposição do ozônio) e aumento da carga negativa do composto orgânico, o que o torna mais reativo. A Figura 2 mostra a remoção de fenol pelos diferentes processos de ozonização estudados em diferentes períodos de tratamento. Após 7 min, a eficiência de remoção de fenol em meio alcalino ( $\mathrm{pH} \mathrm{10)}$ foi de $43 \%$, sendo que em menos de $20 \mathrm{~min}$ de tratamento todo o fenol foi degradado. Em meio ácido ( $\mathrm{pH} 3$ ), observou-se $37 \%$ de remoção do poluente em 7 min de tratamento. $\mathrm{O}$ processo mais efetivo para a remoção de fenol foi $\mathrm{O}_{3} / \mathrm{pH} 3 / \mathrm{Mn}$ (II). A presença dos íons $\mathrm{Mn}^{+2}$ resultou num aumento da eficiência de 12 e $18 \%$ em relação aos processos $\mathrm{O}_{3} / \mathrm{pH} 10$ e $\mathrm{O}_{3} / \mathrm{pH} 3$, respectivamente para um mesmo período de tratamento $(7 \mathrm{~min})$. Este resultado é muito importante, se considerarmos as limitações do processo de ozonização em meio ácido. A presença dos íons $\mathrm{Cu}^{+2}$ resultou numa diminuição da velocidade de degradação do fenol, resultando em apenas $20 \%$ de remoção após 7 min de tratamento. 


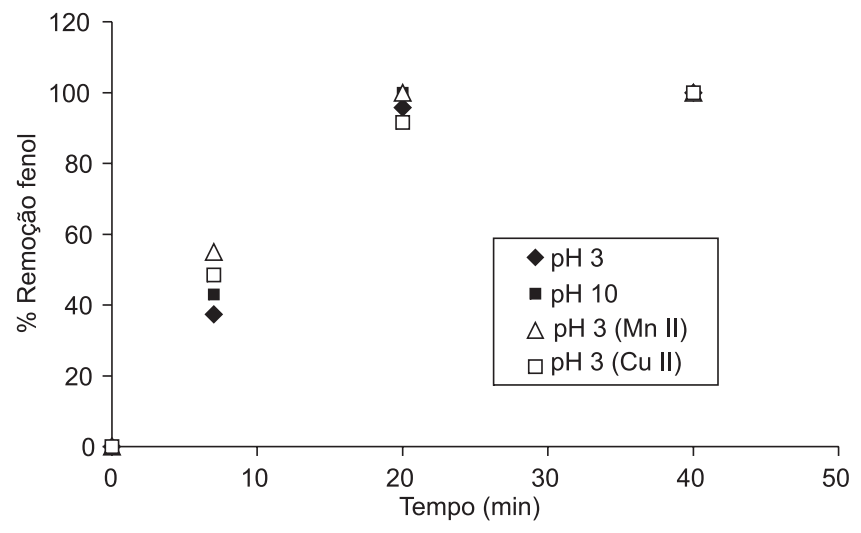

Figura 2. Remoção de Fenol (\%) pelos processos de ozonização: $\mathrm{O}_{3} / \mathrm{pH} 3$;

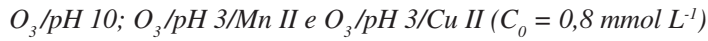

A variação do $\mathrm{pH}$ do meio reacional em função do período de ozonização é mostrada na Figura 3. Os resultados indicam que, independentemente do processo utilizado, compostos ácidos são formados, principalmente nos instantes iniciais do tratamento, o que é facilmente observado no processo $\mathrm{O}_{3} / \mathrm{pH} 10$.

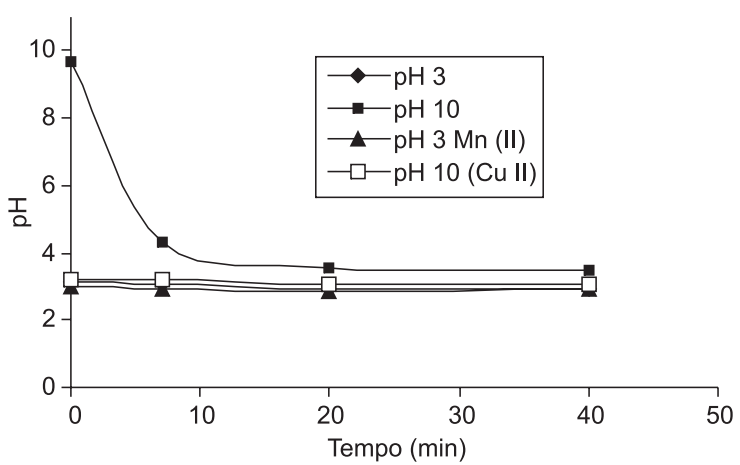

Figura 3. Variação do $\mathrm{pH}$ em função do tempo nos processo de ozonização

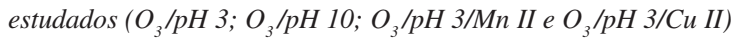

De acordo com Mvula e Sonntag ${ }^{21}$, os principais produtos da ozonólize de fenol são hidroquinona, catecol, 1,4-benzoquinona e cis-cis ácido mucônico (Figura 4). As quantidades encontradas para cada um desses produtos são dependentes do $\mathrm{pH}$ em que a ozonização foi efetuada. Por ex., em pH 10 é possível encontrar-se até $20 \%$ de catecol, enquanto que em $\mathrm{pH} 3$, a quantidade encontrada é de 4,8\%. A formação de hidroquinona e 1,4-benzoquinona durante o processo de ozonização leva a um aumento de toxicidade. Isto demonstra que a completa mineralização do composto é desejada não apenas para garantir a destruição do poluente, mas também para evitar que compostos mais tóxicos sejam formados em função do tratamento aplicado ${ }^{21}$.

A Figura 5 apresenta a remoção de carga orgânica expressa em termos de COT pelos processos de ozonização estudados. O efeito catalítico do íon $\mathrm{Mn}^{+2}$ na degradação de fenol foi muito significativo. Em apenas $7 \mathrm{~min}$ de tratamento, a eficiência aumentou de 4 $(\mathrm{pH} 3)$ para $63 \%(\mathrm{pH} 3 / \mathrm{Mn}(\mathrm{II}))$, sendo mais eficiente que a ozonização realizada em meio alcalino (39\%) na ausência de Mn (II). Entretanto, o efeito catalítico do íon $\mathrm{Cu}^{+2}$ na remoção de carga orgânica foi menos significativo, sendo obtido apenas $22 \%$ de remoção em 7 min de tratamento. Após 40 min de tratamento, a máxima eficiência de remoção obtida foi $88 \%$ pelo processo $\mathrm{O}_{3} / \mathrm{Mn}$ (II). A diferença entre a intensidade catalítica resultante da adição de íons $\mathrm{Cu}^{+2}$ e $\mathrm{Mn}^{+2}$ pode ser explicada por meio de um dos<smiles>O=C1C=CC(=O)C=C1</smiles><smiles>O=C(O)C=CC=CC(=O)O</smiles>

Figura 4. Principais produtos formados na ozonólise de fenol. Baseada na ref. 21

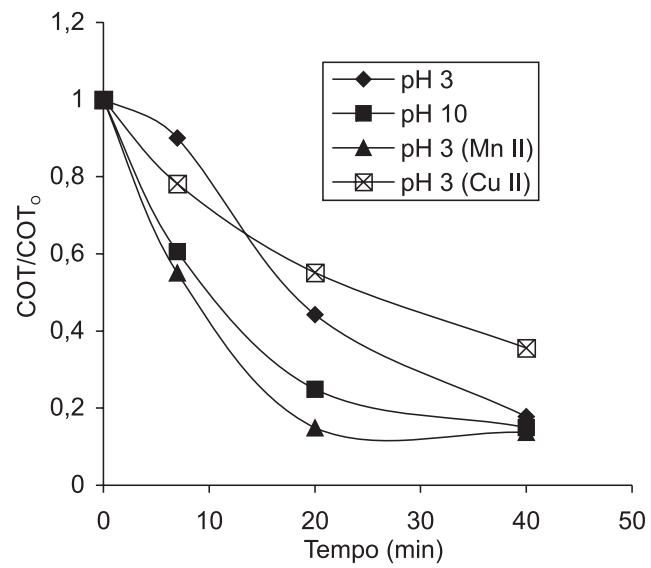

Figura 5. Remoção de carga orgânica (COT/COT $)$ em função do período de tratamento pelos processos de ozonização estudados

mecanismos reacionais apresentados na literatura. Os íons $\mathrm{Mn}^{+2}$ são capazes de decompor o $\mathrm{O}_{3}$ molecular mais efetivamente que os íons $\mathrm{Cu}^{+2}$, resultando em aumento na razão de formação do radical hidroxila, principalmente em meio ácido. É bem estabelecido na literatura que íons metálicos podem iniciar o processo de decomposição do ozônio em meio aquoso levando à formação do radical hidroxila. Os íons presentes na solução iniciam a decomposição do ozônio pela geração do radical $\mathrm{O}_{2}^{-}$. A transferência de um elétron do radical $\mathrm{O}_{2}^{-}$para a molécula de ozônio leva à formação de $\mathrm{O}_{3}^{-}$e, conseqüentemente, do radical hidroxila $\left(\mathrm{OH}^{\bullet}\right)^{14}$, de acordo com outra hipótese mecanística para o aumento da eficiência do processo de ozonização catalisado por íons é possível a formação de complexos entre o metal e as moléculas orgânicas, que são posteriormente oxidadas ${ }^{22}$.

O ozônio consumido em cada um dos processos estudados foi determinado. Observou-se que a presença dos íons metálicos foi capaz de reduzir o consumo de ozônio necessário para degradação do contaminante. O consumo de ozônio pelos processos catalisados pelos íons $\mathrm{Mn}^{+2}, \mathrm{Cu}^{+2}$ e convencional foi 149,198 e $229 \mathrm{mg} \mathrm{L}^{-1}$, respectivamente. Isto indica que a presença do metal de transição influencia o processo de decomposição do ozônio em meio aquoso, sendo necessária menor carga de ozônio para degradação do poluente, o que o torna um processo bastante interessante do ponto de vista econômico ${ }^{12}$.

Comparando-se os resultados obtidos pelos processos catalisados por $\mathrm{Mn}$ (II) e $\mathrm{Cu}$ (II) observou-se que o íon $\mathrm{Mn}^{+2}$ foi o mais eficiente na degradação de fenol, principalmente para remoção de carga orgânica. A remoção de carga orgânica (COT/ 


$$
\begin{aligned}
& \mathrm{O}_{2}^{-}+\mathrm{O}_{3} \longrightarrow \mathrm{O}_{2}+\mathrm{O}_{3}^{-} \\
& \mathrm{O}_{3}^{-}+\mathrm{H}^{+} \longrightarrow \mathrm{HO}_{3} \longrightarrow \mathrm{HO}^{-}+\mathrm{O}_{2}
\end{aligned}
$$

Figura 6. Mecanismo proposto para decomposição catalítica do ozônio

$\mathrm{COT}_{0}$ ) pelo processo convencional $(\mathrm{pH} 3)$ atinge pouco mais de $50 \%$, enquanto que no processo catalisado pelo íon $\mathrm{Mn}^{+2}$ foi superior a $80 \%$. Resultados similares foram obtidos por $\mathrm{Ni}$ et al. ${ }^{12}$ na ozonização catalítica do 2-clorofenol. Dentre os íons estudados, $\mathrm{Mn}^{+2}$ apresentou maior eficiência na degradação do 2-clorofenol. Alguns trabalhos encontrados na literatura descrevem mecanismos de ozonização de ácido oxálico e glicoxálico utilizando $\mathrm{Mn}^{+2}$ como catalisador em um processo homogêneo, sugerindo que os mecanismos seguidos pelo processo catalisado e não catalisado em um mesmo valor de $\mathrm{pH}$ são diferentes, o que foi comprovado através da identificação dos subprodutos formados ${ }^{10}$.

Quanto à remoção de carga orgânica pelo processo de ozonização na presença de $\mathrm{Cu}$ (II) observou-se que o processo é bastante ineficiente. Embora ocorra degradação do fenol, os compostos intermediários formados são provavelmente mais resistentes à oxidação química em comparação com o composto precursor.

\section{CONCLUSÕES}

$\mathrm{O}$ efeito catalítico dos íons $\mathrm{Mn}^{+2}$ e $\mathrm{Cu}^{+2}$ na ozonização de fenol foi estudado. A presença do íon $\mathrm{Mn}^{+2}$ aumentou significativamente a razão de degradação do fenol e reduziu o consumo de ozônio comparativamente aos processos convencionais (via ozônio molecular e radical hidroxila). A remoção de carga orgânica (COT) aumentou de 4 ( $\mathrm{pH} 3$ ) para 63\% (pH 3/Mn (II)) em apenas 7 min de tratamento, enquanto que o consumo de ozônio foi reduzido de 229 para $129 \mathrm{mg} \mathrm{L}^{-1}$ na presença do catalisador. O efeito catalítico do íon $\mathrm{Cu}^{+2}$ foi menos significativo na degradação do fenol.

\section{AGRADECIMENTOS}

À FAPESP pelo apoio financeiro.

\section{REFERÊNCIAS}

1. Tong, S. P.; Leng, W. H.; Zhang, J. Q.; Cao, C. N.; Ozone: Sci. Eng. 2002, 24, 117.

2. Canton, C.; Esplugas, S.; Casado, J.; Appl. Catal., B 2003, 43, 139.

3. Andreozzi, R.; Marotta, R.; Sanchirico, R.; J. Chem. Technol. Biotechnol. 2000, 75, 59.

4. Tong, S. P.; Liu, W. P.; Leng, W. H.; Zhang, Q. Q.; Chemosphere 2003, 50, 1359.

5. Park, J. S.; Choi, H.; Cho, J.; Water Res. 2004, 28, 2285.

6. Legube, B.; Leitner, N. K. V.; Catal. Today 1999, 53, 61.

7. Beltrán, F. J.; Rivas, F. J.; Montero-de-Espinosa, R.; Ind. Eng. Chem. Res. 2003, 42, 3218.

8. Sunder, M.; Hempel, D. C.; Water Res. 1997, 31, 33.

9. Hewes, C. G.; Davinson, R. R.; Water AIChE Symposium Series 1972, 69,71 .

10. Andreozzi, R.; Insola, A.; Caprio, V.; D’Amores, M. G.; Water Res. 1992 , 26, 917.

11. Ma, J.; Graham, N. J. D.; Ozone: Sci. Eng. 1997, 19, 227.

12. Ni, C. H.; Chen, J. N.; Yang, P. Y.; Water Sci. Technol. 2002, 47, 77.

13. Beltrán, F. J.; Rivas, F. J.; Montero-de-Espinosa, R.; Appl. Catal., B 2002, 39, 221

14. Kasprzyk-Hordern, B.; Ziótek, M.; Nawrocki, J.; Appl. Catal., B 2003, 46, 639.

15. Gracia, R.; Cortés, S.; Sarasa, J.; Ormad, P.; Ovelleiro, J. L.; Ozone: Sci. Eng. 1999, 22, 461.

16. Arslan, I.; Akmehmet-Balcioglu, I.; Tuhkanen, T.; Water Sci. Technol. 2000, 42, 13.

17. Paula, M.; Schie, V.; Young, L.Y; Appl. Environ. Microbiol. 1998, 64, 2432.

18. Zilli, M.; Converti, A.; Lodi, A.; Del Borghi, M.; Ferraiolo, G.; Biotechnol. Bioeng. 1993, 41, 693.

19. APHA; Standard methods for examination of water and wastewater, $18^{\text {th }}$ ed., Am. Publ. Health Ass.: New York, 1992.

20. Kunz, A.; Freire, R. S.; Rowedder, J. J. R.; Durán, N.; Quim. Nova 1999, 22,425 .

21. Mvula, E.; von Sonntag, C.; Org. Biomol. Chem. 2003, 1, 1749.

22. Pines, D. S.; Reckhow, D. A.; Environ. Sci. Technol. 2002, 36, 4046. 